Name of the institutes:

${ }^{1}$ Agricultural Institute, Centre for Agricultural Research, Hungarian Academy of Sciences

${ }^{2}$ Georgikon Faculty, University of Pannonia,

\title{
Address of the institutes:
}

${ }^{1}$ Brunszvik u. 2, Martonvásár, H-2462 Hungary

${ }^{2}$ Deák Ferenc u. 10, Keszthely, H-8360 Hungary

Title of the paper: Combined effect of drought stress and elevated atmospheric $\mathrm{CO}_{2}$ concentration on the yield parameters and water use properties of winter wheat (Triticum aestivum L.) genotypes

Running title: Effects of drought and elevated $\mathrm{CO}_{2}$ on water use of wheat

Authors of the paper: Balázs $\operatorname{Varga}^{1}$ (corresponding author), Gyula Vida ${ }^{1}$, Emese Varga-László ${ }^{1}$, Borbála Hoffmann ${ }^{2}$ and Ottó Veisz ${ }^{1}$

Corresponding author: E-mail: varga.balazs@agrar.mta.hu; Phone: +36-22-569-500

Initials of the authors:

B. Varga

G. Vida

E. Varga-László

B. Hoffmann

O. Veisz

Number of tables: 7

Number of figures: 2 


\begin{abstract}
The decline in the amount of water available to plants will lend growing importance to the dynamics of water uptake and to water use efficiency (WUE; $\mathrm{g} \mathrm{kg}^{-1}$ ) in cereals. Water use properties were investigated in terms of the phenological and yield parameters of five winter wheat genotypes in a greenhouse experiment carried out in climate-controlled chambers. The plants were grown either with optimum water supplies or with simulated drought in two phenophases, combined with different $\mathrm{CO}_{2}$ concentrations (ambient and enriched to 700 and $1000 \mathrm{ppm}$ ). Multivariate analysis showed that the $\mathrm{CO}_{2}$ concentration alone significantly influenced water use and water use efficiency but in combination with the cultivars, it also had a significant influence on the grain yield and in a combination with the water supply on the straw biomass, respectively. Higher $\mathrm{CO}_{2}$ concentration significantly reduced the water uptake and improved the WUE values in both the drought treatments. All three factors investigated were found to have a significant influence on the water consumption during the growing season, and the interaction between $\mathrm{CO}_{2}$ and the cultivar influenced WUE. The least change in WUE was detected for Bánkúti 1201 (1.35-1.86 $\mathrm{g} \mathrm{kg}^{-1}$ ), while Mv Mambó, Plainsman V and Mv Toborzó formed a group responding similarly to various environmental effects $\left(1.85-2.55 \mathrm{~g} \mathrm{~kg}^{-1} ; 1.57-2.34 \mathrm{~g}\right.$ $\mathrm{kg}^{-1}$ and $1.45-2.24 \mathrm{~g} \mathrm{~kg}^{-1}$, respectively).
\end{abstract}

Key words: winter wheat, drought stress, elevated $\mathrm{CO}_{2}$, improve productivity, water use efficiency, sustainable agriculture

\title{
Abbreviations
}

B: Biomass; BKT: Bánkúti 1201 wheat variety; CAP: Cappelle Desprez wheat variety; $\mathrm{CO}_{2}$ : Atmospheric carbon dioxide; FNA: First node appearance; GS: Growth stage; GY: Grain yield; H: Heading; HI: Harvest index; MAM: Mv Mambó wheat 
variety; PLA: Plainsman V wheat variety; TGW: Thousand-grain weight; TOB: Mv Toborzó wheat variety; WU: Water use; WUE: Water use efficiency.

\section{Introduction}

One of the greatest challenges that will face mankind over the next few decades will be the need to satisfy the food requirements of a growing population while the available freshwater reserves are declining steadily (Pask and Reynolds 2013). Wheat production will play an important role in the food supply of the future, but it is highly sensitive to climatic and environmental variations (Parry et al. 1999, Semenov and Stratonovitch 2013). Water deficit is one of the main limiting factors for cereal production in many parts of the world, especially in arid and semi-arid regions (Shahbaz et al. 2009). When endeavouring optimum yields with limited water supplies, farmers have the choice of using new water-saving technologies or growing varieties that use water more efficiently (Jabran et al. 2015; Zhang et al. 2008). The limitations in water supplies make it especially important to utilise the available soil water reserves as efficiently as possible, which will not always mean achieving the highest possible yields (Passioura 2002). Water use efficiency (WUE; $\mathrm{g} \mathrm{kg}^{-1}$ ) is a key indicator of drought tolerance. Numerous authors in various parts of the world have demonstrated substantial differences between the WUE values of individual cereal species (Rizza et al. 2012, Zhang et al. 2013; Morell et al. 2011), but have also emphasised the fact that changes in WUE are especially important if the water supply to the plants is limited (Varga et al. 2013). Evans and Sadler (2008) reported that much additional information is required about actual crop evapotranspiration and water use levels when plants suffer different levels of stress during different growth stages. As the growth characteristics and tolerance of cereal plants are relatively location-specific, crop breeding will have the greatest impact on 
increasing water use efficiency by selecting varieties with optimal growing season length and ripening dates for each region (Passioura 2012; Singh et al. 1991). Earlier studies demonstrated that the effect of water deficit on plant phenological parameters, water consumption and WUE depended on the development phase of the wheat exposed to the stress (Fang et al. 2015; Varga et al. 2013). Crop breeding has already contributed to an increase in WUE and is expected to play an important role in the future (Passioura 2012). A change in WUE may represent one of the most significant plant responses to elevated $\mathrm{CO}_{2}$ (Rogers et al. 1994). Plant growth depends on the water stored in the soil or that accumulated through rainfall and irrigation. To determine the abiotic plasticity of individual varieties, the phenotypic and physiological properties of the plants need to be tested under non-optimal climatic conditions (Dahal et al. 2014; Ehdaie et al. 2012; Francia et al. 2011; Hoffmann 2008). The rise in $\mathrm{CO}_{2}$ concentration has both direct and indirect effects on agricultural production. It has been predicted that the global atmospheric $\mathrm{CO}_{2}$ concentration may be as high as 700 ppm by the end of the 21 st century. For plants the $\mathrm{CO}_{2}$ present in the atmosphere is a nutrient, representing one of the raw materials required for photosynthesis. An increase in the atmospheric $\mathrm{CO}_{2}$ concentration has a direct effect in mitigating drought damage via an increase in the fertile tillers number and a reduction in stomatal resistance (Tausz-Posch et al. 2015; Tuberosa 2012; Wall, 2001). Many experiments have also been carried out to determine the morphological and physiological responses of various plant species to the interaction between elevated $\mathrm{CO}_{2}$ concentration and water stress, but it has become clear that the magnitude of the $\mathrm{CO}_{2}$ effect is very difficult to predict (Harnos 2002; Bencze et al. 2000). Elevated $\mathrm{CO}_{2}$ concentrations can improve biomass and yield in $\mathrm{C} 3$ crops by increasing photosynthesis and decreasing photorespiration, but there are large 
differences between species in the magnitude of the yield stimulation (Kimball et al., 2002). No significant yield stimulation has been found so far in C4 crops, at least under well-watered conditions, because $\mathrm{C} 4$ photosynthesis is saturated at ambient $\mathrm{CO}_{2}$. However, in all crops (both $\mathrm{C} 3$ and $\mathrm{C} 4$ ), higher $\mathrm{CO}_{2}$ concentrations reduce stomatal conductance and transpiration and improve water-use efficiency, i.e. crops will have a reduced demand for water (Bender and Weigel 2011). Elevated WUE at higher $\mathrm{CO}_{2}$ was attributed by Tuba et al. (2007) not only to an increase in net photosynthesis even in the case of moderate water deficiency, but also to the permanently low values of evapotranspiration. In another study, the reduction in evapotranspiration and the enhancement of net photosynthesis due to elevated $\mathrm{CO}_{2}$ increased both the instantaneous and whole-plant WUE under both irrigated and drought-stressed conditions (Robredo et al. 2007). Elevated $\mathrm{CO}_{2}$ concentration enhanced drought tolerance to a greater extent in a sensitive variety than in more tolerant genotypes; sensitive plants had a higher assimilation rate at elevated than at ambient $\mathrm{CO}_{2}$ under moderate drought stress, while more tolerant genotypes had similar values at both $\mathrm{CO}_{2}$ concentrations even under mild stress (Bencze et al. 2000).

The aim of the present experiment was to determine (i) how the atmospheric $\mathrm{CO}_{2}$ concentration influence the water use and water use efficiency of individual cultivars, and (ii) whether there was any difference in the $\mathrm{CO}_{2}$ responses of the cultivars in terms of WUE, (iii) whether raising the $\mathrm{CO}_{2}$ concentration to various levels modified the response of the cultivars in terms of phenological and yield parameters or water use properties, and (iv) which phenological and yield parameters influenced water consumption during the vegetation period and which affected WUE when drought was simulated by water withholding in various phenophases. 


\section{Materials and Methods}

\subsection{Plant Materials and Experimental Layout}

Five winter wheat (Triticum aestivum L.) cultivars (Mv Toborzó /TOB/, Mv Mambó /MAM/, Bánkúti 1201 /BKT/, Plainsman V /PLA/ and Cappelle Desprez /CAP/) were examined in climate-controlled greenhouse chambers at the Centre for Agricultural Research, Hungarian Academy of Sciences. Plainsman V (droughttolerant) and Cappelle Desprez (drought-sensitive) were used as check cultivars. Bánkúti 1201 is an old Hungarian landrace, with tall plants and excellent baking quality due to its special storage protein composition. Mv Toborzó has moderate plant height and is the earliest cultivar in the Martonvásár collection. Mv Mambó is a hard-grained winter wheat with high yielding potential, which has proved to have excellent abiotic stress tolerance in numerous experiments (Varga et al. 2013, Varga et al. 2015). After 42 days of vernalisation at $4^{\circ} \mathrm{C}$, eight seedlings were planted in each pot, containing $10,000 \mathrm{~cm}^{3}$ of a $3: 1: 1(\mathrm{v} / \mathrm{v})$ mixture of soil, sand and humus. The plants were watered three times a week and nutrient solution was added once a week until the start of the drought treatment. The nutrient supplies were the same in all the treatments, regardless of water consumption. Water deficit was simulated by complete water withholding in two phenophases, at first node appearance (Growth stage, GS 21, Zadoks et al. 1974) (FNA) or at heading (GS 60) (H). The treated plants were stressed on a single occasion, and the stress treatment was started when $50 \%$ of the plants reached the required developmental stage. The experimental design involved 5 genotypes, 3 stress treatments (Control, FNA and $\mathrm{H}$ ), three $\mathrm{CO}_{2}$ levels (ambient $\sim 400$ ppm; $~ 700$ ppm and $\sim 1000$ ppm) and 3 replicates. For plants given optimum water supplies the soil water content was maintained at $60 \%$ of the soil water-holding capacity, equivalent to a volumetric water content (v/v\%) of 20 
$25 \%$. The soil water content was measured using $5 \mathrm{TE}$ soil water meters and the data were recorded with an EM50 data logger (Decagon Devices Ltd., USA). The soil water content dropped from the control level to $3-5 \mathrm{v} / \mathrm{v} \%$ by the end of the stress treatment. After the stress had been simulated for 7 to 10 days, watering was recommenced and the plants were given optimum supplies until full maturity. The water consumption was determined by weighing the pots on a digital balance (Mettler-Toledo Ltd., USA). To minimize evaporation, the soil surface was covered with polythene. The air temperature and additional light intensity of the greenhouse chamber were regulated automatically. The climatic program was based on the analysis of a 50-year time series for Hungary, which is routinely used in phytotron studies (Tischner, 1997). The air temperature was increased from the initial $10-12^{\circ} \mathrm{C}$ to $24-26^{\circ} \mathrm{C}$ over a period of 16 weeks, while air humidity was kept between $60 \%$ and $80 \%$ and was regulated by ventilating the greenhouse chambers. Whenever necessary, the natural light intensity was enhanced by artificial illumination to a value of $500 \mu \mathrm{mol} \mathrm{m} \mathrm{m}^{-2} \mathrm{~s}^{-1}$ at the beginning of the vegetation period, which was gradually increased to $700 \mu \mathrm{mol} \mathrm{m} \mathrm{m}^{-2}$. The plants were grown in three greenhouse chambers of similar type using the same climatic conditions, with the exception of the atmospheric $\mathrm{CO}_{2}$ concentration, which was set to the ambient gas concentration of $\sim 400 \mathrm{ppm}$ in the control chamber and to $\sim 700 \mathrm{ppm}$ and $\sim 1000 \mathrm{ppm}$ in the other two. The $\mathrm{CO}_{2}$ was introduced into the chambers through a network of perforated pipes placed at a height of $0.5 \mathrm{~m}$ above the plants, and uniform distribution was achieved by means of ventilation.

\subsection{Analysis}

The effect of water deficiency was studied by measuring changes in the grain yield (GY; g), thousand-grain weight (TGW;g) and aboveground biomass (B;g). The 
harvest index (HI; \%) was calculated by dividing the grain yield by the total aboveground biomass. The total quantity of water used was measured throughout the vegetation period. The water use efficiency (WUE; $\mathrm{g} \mathrm{kg}^{-1}$ ) was calculated by dividing the grain yield ( $\mathrm{g}$ ) by the water used during the vegetation period (WU; kg/pot) (Doorenbos and Pruitt 1977). The dynamics of water uptake for the individual cultivars was determined by calculating the water quantity utilised during each developmental phase. Water consumption was measured by weighing the pots and replacing the water on a weight basis.

\subsection{Statistical analysis}

The experimental design involved five genotypes, three watering treatments in three replicates, and three $\mathrm{CO}_{2}$ treatments. Multivariate analysis was applied to determine the interactions between the factors using the MSTAT-C 1.42 program package (Michigan State University, USA), while the Pearson correlation analysis module of the SPSS 16.0 program package (IBM Inc, USA) was used to study correlations between WU, WUE and various phenological and yield parameters.

\section{Results}

\subsection{Analysis of yield components}

When the separate effects of the individual factors were examined, both the cultivar and the water supply level were found to have a significant influence on the yields throughout the experiment, but the effect of the $\mathrm{CO}_{2}$ concentration was not significant in itself (Table 1). In combination with the cultivar and water supply effects, the $\mathrm{CO}_{2}$ treatment significantly modified the results, which could be attributed to the differing $\mathrm{CO}_{2}$ responses of the cultivars. When the grain yield was analysed, no $\mathrm{CO}_{2}$ response was detected for cultivars MAM and BKT, averaged over 
the water supply levels, while for cultivars PLA and TOB there was only a substantial increase in grain yield at the $1000 \mathrm{ppm}$ concentration.

Table 1 Grain yield $\left(\mathrm{g} \mathrm{pot}^{-1}\right)$ of winter wheat cultivars in various treatments (MAM: Mv Mambó; BKT: Bánkúti 1201; CAP: Cappelle Desprez; PLA; Plainsman V; TOB: Mv Toborzó; FNA: first node appearance)(Bold indicates the means of one factor and italic the means of two or three factors)

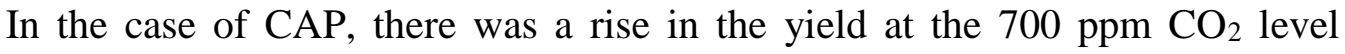
compared with $400 \mathrm{ppm}$, but a considerable decrease was recorded when the $\mathrm{CO}_{2}$ concentration was enriched to $1000 \mathrm{ppm}$. Increasing the atmospheric $\mathrm{CO}_{2}$ concentration to $1000 \mathrm{ppm}$ had a positive effect on the yield of TOB in both the FNA and $\mathrm{H}$ treatments, compared to the $400 \mathrm{ppm}$ control. The negative effect of water deficit on the yield of MAM when applied in the early phase of development was partially counterbalanced by a higher $\mathrm{CO}_{2}$ concentration, but when this cultivar was exposed to water deficit at heading, the unfavourable effect on the yield quantity increased as the $\mathrm{CO}_{2}$ concentration rose. When the yields achieved at various water supply levels were averaged over the cultivars, the FNA and $\mathrm{H}$ treatments had a similarly severe effect on the yield at the various carbon dioxide levels. When the cultivars were examined separately, however, considerable differences were observed between the two drought stress treatments in terms of the direction of the change generated in the grain yield by water deficit and enhanced atmospheric $\mathrm{CO}_{2}$ concentration. In the case of Mv Mambó the highest grain yield was recorded in the FNA treatment at the 1000 ppm concentration, while this $\mathrm{CO}_{2}$ level resulted in considerably lower yields when applied at heading than in the $\mathrm{C}$ and FNA treatments (Table 1). 
The statistical evaluation of the straw biomass data revealed that the individual effects of higher atmospheric $\mathrm{CO}_{2}$ concentration, cultivar and water supply level were all significant (Table 2).

Table 2 Straw biomass $\left(\mathrm{g} \mathrm{pot}^{-1}\right)$ of winter wheat cultivars in various treatments (MAM: Mv Mambó; BKT: Bánkúti 1201; CAP: Cappelle Desprez; PLA; Plainsman V; TOB: Mv Toborzó; FNA: first node appearance)(Bold indicates the means of one factor and italic the means of two or three factors)

Due to the different genetic backgrounds of the cultivars, substantial differences were detected between the genotypic responses to both water withholding and changes in $\mathrm{CO}_{2}$ concentration. Far higher straw biomass values were recorded at enhanced $\mathrm{CO}_{2}$ concentration, especially when drought stress was simulated at first node appearance. This was confirmed by the fact that the combined effect of $\mathrm{CO}_{2}$ and water supplies was found to be significant too.

Averaged over the water supply levels and $\mathrm{CO}_{2}$ concentrations, the lowest straw biomass was recorded for TOB, higher and similar values for PLA and MAM, and the highest values for BKT and CAP. Averaged over the water supply levels, there was no significant difference between the straw biomass values at the diverse $\mathrm{CO}_{2}$ concentrations for MAM and BKT, but the cultivars PLA and TOB responded to the $1000 \mathrm{ppm} \mathrm{CO}_{2}$ level with a substantially higher straw biomass compared with the 400 and 700 ppm levels. This difference was especially noteworthy in the control and for plants stressed at first node appearance (Table 2).

Table 3 Thousand-grain weight $(\mathrm{g})$ of winter wheat cultivars in various treatments 
(MAM: Mv Mambó; BKT: Bánkúti 1201; CAP: Cappelle Desprez; PLA; Plainsman V; TOB: Mv Toborzó; FNA: first node appearance)(Bold indicates the means of one factor and italic the means of two or three factors)

The thousand-grain weight is one of the most useful parameters for detecting environmental stress effects, as its value may be influenced not only by the seedsetting problems caused by water deficit but also by grain-filling anomalies (Table 3). In the present experiment all three factors had a significant influence on the TGW. In all the treatments, lower values of TGW were recorded for cultivars PLA and CAP than for MAM, TOB and BKT. In the case of optimum water supplies, the TGW generally declined at atmospheric $\mathrm{CO}_{2}$ concentrations of 700 and 1000 ppm, compared with that of plants grown at $400 \mathrm{ppm}$, but this was not true of plants exposed to drought stress. This could indicate that the higher gas concentration mitigated the unfavourable effects of water withholding. It was found that both water withholding (especially in the later stage of development) and elevated atmospheric $\mathrm{CO}_{2}$ concentration led to a reduction in TGW. The statistical analysis also revealed significant changes in TGW as a result of the interactions between $\mathrm{CO}_{2}$ concentration and cultivar, and between cultivar and water supplies (Table 3 ).

Table 4 Harvest index (\%) of winter wheat cultivars in various treatments

(MAM: Mv Mambó; BKT: Bánkúti 1201; CAP: Cappelle Desprez; PLA; Plainsman V; TOB: Mv Toborzó; FNA: first node appearance)(Bold indicates the means of one factor and italic the means of two or three factors)

In the case of HI, changes could be detected due to both cultivar and water supplies alone, while the $\mathrm{CO}_{2}$ concentration had no significant effect on $\mathrm{HI}$ in itself (Table 4). When drought was simulated at first node appearance, a substantial drop in 
HI was observed in cultivars MAM and TOB, but this may have been due to the fact that these cultivars had significantly higher HI values than the other genotypes when given optimum water supplies. Averaged over the cultivars, there was a considerable decline in $\mathrm{HI}$ even in the FNA treatment, irrespective of the $\mathrm{CO}_{2}$ concentration, while this reduction increased substantially compared with the control in plants stressed at heading. In general, lower $\mathrm{HI}$ values were recorded at higher $\mathrm{CO}_{2}$ concentrations. The correlations detected for straw biomass showed that this parameter decreased to a smaller extent than the grain yield at higher $\mathrm{CO}_{2}$ level, and this was responsible for the changes observed in HI. Averaged over the water supply levels, it was found for all the cultivars that plants grown at the highest, 1000 ppm carbon dioxide concentration had lower HI values than those grown at $400 \mathrm{ppm}$. For plants grown at various $\mathrm{CO}_{2}$ concentrations it could be seen, averaged over the cultivars, that while the 700 ppm concentration caused no significant reduction in HI, and even led to a slight increase in the FNA treatment, the $1000 \mathrm{ppm} \mathrm{CO}_{2}$ concentration resulted in lower HI values than the $400 \mathrm{ppm}$ concentration at all three water supply levels in the $\mathrm{H}$ treatment, compared with C and FNA (Table 4).

\subsection{Trends in water uptake and WUE}

When evaluating the water uptake of plants during the vegetation period it was found that all three factors alone had a significant influence on the water uptake, while the effect of $\mathrm{CO}_{2}$ also exhibited a significant interaction with cultivar and water supplies (Table 5). When grown with optimum water supplies, the lowest WU value was recorded for TOB, with higher values for PLA and MAM and the highest for BKT and CAP. The genotypes exhibited diverse responses to $\mathrm{CO}_{2}$. Cultivars MAM, BKT and TOB responded positively to $\mathrm{CO}_{2}$, but this was not true for CAP or PLA. 
Table 5 Water consumption $\left(\mathrm{kg} \mathrm{pot}^{-1}\right)$ of winter wheat cultivars in various treatments (MAM: Mv Mambó; BKT: Bánkúti 1201; CAP: Cappelle Desprez; PLA; Plainsman V; TOB: Mv Toborzó; FNA: first node appearance)(Bold indicates the means of one factor and italic the means of two or three factors)

When drought stress was simulated at first node appearance, there was generally a drop in the water uptake of the cultivars during the growing season, but this decline tended to be greatest at the $400 \mathrm{ppm} \mathrm{CO}_{2}$ level, with a less pronounced decrease at higher concentrations (Figure 1). The smallest changes in WU were observed at $1000 \mathrm{ppm}$. Averaged over the cultivars, the water uptake was found to decrease parallel with the rise in $\mathrm{CO}_{2}$ concentration in the case of optimum water supplies. The positive effect of $\mathrm{CO}_{2}$ could also be detected in the drought stress treatments, but in the $\mathrm{H}$ and FNA treatments the water uptake was not lower at 1000 ppm than it was at $700 \mathrm{ppm}$. Averaged over the $\mathrm{CO}_{2}$ concentrations, the lowest water uptake was recorded for TOB when water was withheld at first node appearance, with higher values for PLA and MAM and the highest for CAP and BKT (Table 5).

Figure 1 Combined effects of water shortage and elevated $\mathrm{CO}_{2}$ concentrations on the water use $\left(\mathrm{kg} \mathrm{pot}^{-1}\right)$ of winter wheat varieties (significant $\mathrm{CO}_{2}$ effect is indicated) (MAM: $M v$ Mambó; BKT: Bánkúti 1201; CAP: Cappelle Desprez; PLA; Plainsman V; TOB: Mv Toborzó; FNA: first node appearance)

Water deficit at heading resulted in a drop in the $\mathrm{WU}$ value as the $\mathrm{CO}_{2}$ level rose, with the exception of TOB. While WU values similar to those recorded in the FNA treatment were found for most of the cultivars at $400 \mathrm{ppm}$, the water uptake tended to decline at higher $\mathrm{CO}_{2}$ concentrations (Figure 1). An intensive drop in water uptake has an unfavourable effect on plants, as it may result not only in a reduction in the grain yield, but also in forced ripening, e.g. in the case of Mv Mambó. 
An analysis of water use efficiency revealed that all three factors had significant effects when applied alone, but the interaction between $\mathrm{CO}_{2}$ concentration and water withholding was not significant (Table 6). The following WUE values were recorded in the treatments for each cultivar: MAM: $1.85-2.55 \mathrm{~g} \mathrm{~kg}^{-1}$; BKT: 1.35-1.86 g kg $\mathrm{kg}^{-1}$. The least change in WUE was detected for BKT, while MAM, PLA and TOB formed a group responding similarly to various environmental effects. The greatest variability was exhibited by CAP. When grown with optimum water supplies, differences were found in the $\mathrm{CO}_{2}$ responses of the cultivars. In the case of MAM and TOB, WUE rose parallel with the increase in atmospheric $\mathrm{CO}_{2}$ concentration, while PLA and BKT had significantly better values of WUE at $700 \mathrm{ppm}$ compared with $400 \mathrm{ppm}$, but the water use efficiency did not improve further at a concentration of $1000 \mathrm{ppm}$ (Figure 2). In the control and FNA treatments the WUE value of CAP was better at $700 \mathrm{ppm}$ than at $400 \mathrm{ppm}$, but dropped to below the value recorded at $400 \mathrm{ppm}$ when the plants were grown at the $1000 \mathrm{ppm}$ concentration. In response to water withholding at heading, the WUE values decreased compared to those recorded in the control water supply treatment, but averaged over the cultivars the $1000 \mathrm{ppm}$ concentration had a more favourable effect than in the FNA treatment.

Table 6 Water use efficiency $\left(\mathrm{g} \mathrm{kg}^{-1}\right)$ of winter wheat cultivars in various treatments (MAM: Mv Mambó; BKT: Bánkúti 1201; CAP: Cappelle Desprez; PLA; Plainsman V; TOB: Mv Toborzó; FNA: first node appearance)(Bold indicates the means of one factor and italic the means of two or three factors)

Among the cultivars tested, the $\mathrm{CO}_{2}$ response of TOB was the most intensive in the $\mathrm{H}$ treatment, as also observed in the control and FNA treatments (Figure 2). Averaged over the cultivars an increase in the $\mathrm{CO}_{2}$ concentration was associated with 
a rise in the WUE values, especially in the control and in plants stressed at heading (Table 6). The highest WUE values were recorded for drought-stressed plants of cultivar MAM treated at first node appearance and grown at a $\mathrm{CO}_{2}$ concentration of 700 ppm, while for PLA the WUE values were extremely high at all three $\mathrm{CO}_{2}$ concentrations when the plants were exposed to stress at heading. The WUE value of the cultivar MAM did not drop below $2.0 \mathrm{~g} \mathrm{~kg}^{-1}$ at either of the enhanced $\mathrm{CO}_{2}$ concentrations, regardless of the water supplies, and was only slightly below this value at the $400 \mathrm{ppm}$ concentration (Table 6).

Figure 2 Combined effects of water shortage and elevated $\mathrm{CO}_{2}$ concentrations on the water use efficiency $\left(\mathrm{g} \mathrm{kg}^{-1}\right)$ of winter wheat varieties (significant $\mathrm{CO}_{2}$ effect is indicated) (MAM: Mv Mambó; BKT: Bánkúti 1201; CAP: Cappelle Desprez; PLA; Plainsman V; TOB: Mv Toborzó; FNA: first node appearance)

The short-season cultivars TOB and PLA exhibited the lowest WUE values in the FNA treatment, but the favourable effects of higher $\mathrm{CO}_{2}$ concentrations were most pronounced in this treatment. In the $\mathrm{H}$ treatment the highest, $1000 \mathrm{ppm} \mathrm{CO}_{2}$ concentration fully compensated for the unfavourable effect of water withholding on WUE in these cultivars, indicating that the reduction in water use was paralleled by a decrease in the grain yield. Averaged over the water supply levels, elevated $\mathrm{CO}_{2}$ concentration was found to improve the WUE values for all cultivars except CAP (Table 6).

\subsection{Correlation analysis}

When all the treatments were included in the analysis, the spike and tiller number, the plant height, the total and straw biomass and the harvested grain yield were found to have the greatest positive influence on water consumption, and higher tiller and spike numbers and greater plant height had a negative effect on WUE 
(Table 7). The closest correlation was detected between the total biomass, the straw biomass and the water use parameters. The dry straw biomass was in positive correlation with the water consumption, while the correlation with WUE was less close. The atmospheric $\mathrm{CO}_{2}$ concentration did not influence either the WU or the WUE values in any of the treatments.

Table 7 Correlation between water use parameters, environmental factors and plant

$$
\text { phenological and yield properties }
$$

(FNA: first node appearance; H: heading; WU: total water use; WUE: water use efficiency; TGW: thousand-grain weight; HI: harvest index)(Bold indicates significant correlation)

At optimum water supplies, correlation analysis on phenological and yield traits and water consumption parameters revealed that the results obtained for the whole experiment were also valid in this case. The only difference was that the tiller numbers had no detectable effect on WU and no correlation was observed between the spike and tiller number and WUE. There was also no correlation between the thousand-grain weight and WU or WUE, and only a weak relationship was found between TGW and WUE when all the treatments were analysed together.

When drought was simulated at first node appearance, no correlation was detected between the tiller and spike numbers and WUE, while the plant height and straw biomass were only correlated with WU. Higher grain yield had a significant positive effect on water consumption in this treatment. Although greater biomass increased water consumption in the case of water withholding in the early developmental phase, it had no effect on WUE.

The spike and tiller numbers, which had no effect on WU or WUE in the FNA treatment, significantly influenced these parameters when drought was simulated at heading. Greater tiller and spike numbers resulted in higher water consumption and 
less efficient water use. The plant height had no influence on the water use parameters in the $\mathrm{H}$ treatment.

No close correlations between WU and either grain yield or thousand-grain weight were detected in plants treated at heading. While the biomass only had a positive influence on WU in the FNA treatment, in the $\mathrm{H}$ treatment a significant negative correlation was also found with WUE (Table 7).

\section{Discussion}

It can be seen from the results of simulation models based on the SRES (Special Report on Emissions Scenarios) climate scenarios that a slight decline can be expected in field crop production, though there may be considerable differences depending on the extent to which the positive effects of rising $\mathrm{CO}_{2}$ concentrations are exploited (Parry et al. 2004). The direction of climate change is also of outstanding importance, as some authors consider that positive changes in climatic conditions, combined with developments in cultivation technologies, may increase potential wheat yields by $37-101 \%$ by 2050 (Ewert et al. 2005). In the present study a rise in the $\mathrm{CO}_{2}$ concentration did not result in changes in the grain yield under optimum water supplies, averaged over the cultivars, but different $\mathrm{CO}_{2}$ reactions were detected for the varieties investigated. At a $\mathrm{CO}_{2}$ concentration of $400 \mathrm{ppm}$ water deficit at first node appearance caused a $25.1 \%$ loss of yield, while at $700 \mathrm{ppm}$ this figure was even higher (30.1\%). To some extent, however, the highest, $1000 \mathrm{ppm} \mathrm{CO}_{2}$ level was able to counteract the unfavourable effects of water deficit in this early stage of development, as a yield reduction of only $20.6 \%$ was detected compared with plants grown at the same $\mathrm{CO}_{2}$ level with optimum water supplies. When drought stress was simulated at heading a similar tendency was observed. The models run by Ewert et al. (2002) showed that enhanced $\mathrm{CO}_{2}$ concentration had a greater effect on the yield 
if the higher $\mathrm{CO}_{2}$ level was combined with drought stress, The present work, however, suggested that the interaction between yield and water deficit depended partly on the atmospheric $\mathrm{CO}_{2}$ concentration and partly on the phenophase in which drought stress was applied. Liu et al. (2013) demonstrated that reducing water use by $16 \%$ compared with the normal water supply level, if divided evenly over the whole season, had no effect on the grain production of winter wheat. The results obtained in the present work, however, indicated that the simulation of intensive drought in any phenophase led to a substantial reduction in the yield, especially in less stresstolerant genotypes, even if the plants were given optimum water supplies after the stress period.

It was shown that elevated $\mathrm{CO}_{2}$ concentration increased biomass and yield to some extent in C3 and C4 crops under drought conditions (Ottman et al. 2001), while Li et al. (2003) found that the dry biomass was significantly greater in well-watered plants than in the drought treatment at both $\mathrm{CO}_{2}$ concentrations tested. Opposite tendencies were detected at depleted $\mathrm{CO}_{2}$ concentration, which resulted in a reduction in photosynthetic acclimation, plant biomass and harvest index (Aljazairi and Nogues, 2015). The substantial increase in the $\mathrm{CO}_{2}$ concentration to $1000 \mathrm{ppm}$ had no significant effect on the grain yield in the present experiments, but the straw biomass was found to decline slightly in response to enhanced $\mathrm{CO}_{2}$ at optimum water supplies, averaged over the cultivars. In the case of drought-stressed plants, although the straw biomass tended to decrease in both treatments, this reduction was less pronounced at $1000 \mathrm{ppm}$ than at $400 \mathrm{ppm}$ or $700 \mathrm{ppm} \mathrm{CO}_{2}$.

Based on results achieved in climatic chambers, Kang et al. (2002) reported that doubling the $\mathrm{CO}_{2}$ concentration reduced evapotranspiration by $17.4 \%$ in wellwatered wheat plants, while the reduction was less pronounced in the drought 
treatment $(8.5 \%)$. It was stated by Hunsaker et al. (1996) that the water consumption of wheat plants grown at enhanced $\mathrm{CO}_{2}$ concentration declined by $5.8 \%$ over the growing season in the case of optimum water supplies, while this decrease was only $0.9 \%$ when water supplies were limited. In studies on oat (Avena nuda) plants, Lin et al. (2012) found a 9.97-12.46\% drop in water consumption in response to moderate drought stress, with an improvement of $0-9.1 \%$ in WUE, but this was associated with a grain yield reduction of 2.1-12.76\%. The present experiments partly confirmed and partly contradicted these results. At optimum water supplies it was found that a rise in the atmospheric $\mathrm{CO}_{2}$ concentration reduced the water consumption of winter wheat by $14.3 \%$ and $16.6 \%$ at $\mathrm{CO}_{2}$ concentrations of $700 \mathrm{ppm}$ and $1000 \mathrm{ppm}$, respectively, and similar results were obtained when drought was simulated in the heading stage. This suggested that if conditions were optimum prior to heading, the favourable effect of $\mathrm{CO}_{2}$ on the water consumption continued to be manifested. A similar correlation was detected for water withholding at first node appearance in plants grown at $700 \mathrm{ppm} \mathrm{CO}_{2}$ concentration. This can be attributed chiefly to the extremely high straw biomass obtained in this treatment, as the resumption of optimum water supplies after the drought stress, combined with the high atmospheric $\mathrm{CO}_{2}$ concentration, led to intensive tiller formation.

$\mathrm{Li}$ et al. (2013) reported that elevated atmospheric $\mathrm{CO}_{2}$ concentration stimulated the growth of soybean plants and improved their WUE values, especially in the case of normal water supplies, but the high gas concentration was not found to improve the stress tolerance of the plants. The present work confirmed the results of Li et al. (2013), as enhanced atmospheric $\mathrm{CO}_{2}$ concentration was found to improve WUE to the greatest extent in the case of optimum water supplies. In field experiments Kang et al. (2002) recorded WUE values of $0.73-0.93 \mathrm{~kg} \mathrm{~m}^{-3}$ for winter 
wheat under rainfed conditions, while these rose to $0.77-1.46 \mathrm{~kg} \mathrm{~m}^{-3}$ in the case of supplementary irrigation. Maintaining water supplies at the optimum level resulted in better WUE values. The experiments of Qiu et al. (2008) demonstrated that the WUE of winter wheat ranged from $1.13-2.13 \mathrm{~kg} \mathrm{~m}^{-3}$ depending on the intensity of irrigation. In the present work significant differences were found in the WUE values of winter wheat as a function of the cultivar and the water supply level. Averaged over the cultivars, WUE values of $1.73,2.05$ and $2.04 \mathrm{~g} \mathrm{~kg}^{-1}$ were recorded under optimum irrigation at atmospheric $\mathrm{CO}_{2}$ concentrations of 400, 700 and $1000 \mathrm{ppm}$, respectively. These results are similar to those published by Qiu et al. (2008). The simulation of drought at first node appearance led to WUE values of 1.62, 1.84 and $1.68 \mathrm{~g} \mathrm{~kg}^{-1}$ at the 400, 700 and $1000 \mathrm{ppm}$ levels, while for water deficit at heading these values were $1.64,1.77$ and $1.87 \mathrm{~g} \mathrm{~kg}^{-1}$, averaged over the cultivars.

The models run by Guo et al. (2010) revealed that the evapotranspiration of winter wheat on the North China Plain could be expected to decrease by $2-14 \%$ by 2030 as a consequence of increasing atmospheric $\mathrm{CO}_{2}$ concentration. The results showed that the WUE of winter wheat was likely to improve by $28.01 \%$ by 2030 , by $55.8 \%$ by 2060 and by as much as $78.1 \%$ by 2090 . In most plant species elevated $\mathrm{CO}_{2}$ concentration was found to reduce the stomatal conductance by $33-50 \%$ and the leaf transpiration rate by $20-27 \%$, while elevated $\mathrm{CO}_{2}$ increased the canopy WUE by 15-50\% compared with the ambient $\mathrm{CO}_{2}$ concentration (Zhang et al. 1999). The results of the present experiment demonstrated that changes on this scale were not likely if the joint effects of cultivar, water supplies and various levels of atmospheric $\mathrm{CO}_{2}$ concentration were considered. It was found that increasing the $\mathrm{CO}_{2}$ level to 700 ppm would improve the WUE value by $9.93-19.65 \%$ at various water supply levels, 
whereas the increase at the $1000 \mathrm{ppm}$ concentration would only be $3.53-16.76 \%$ compared with the $400 \mathrm{ppm} \mathrm{CO}_{2}$ level measured today.

It was reported by Zhang et al. (2008) that moderate water deficit in the grainfilling period stimulated the mobilisation of assimilates from the vegetative organs to the grains, leading to higher yields and better WUE values. Mitchell et al. (1998) found that moderate plant size and straw biomass could be important parameters in determining the stress tolerance of plants in an unfavourable environment. The present study suggested that a difference could be detected in the parameters determining WU and WUE, depending on the phenophase in which water deficit occurred. The aboveground biomass, and particularly the straw biomass, was positively correlated with water use in all the treatments, but these traits were not decisive for WUE when water was withheld at first node appearance. Blum (2005) reached the conclusion that leaf size and the number of tillers and spikes could also have a substantial effect on the water consumption and WUE when plants were exposed to drought stress. This was partially confirmed by the present study, as a close correlation was detected between the tiller and spike number and the WU and WUE values. The former was negatively and the latter positively influenced by the tiller and spike number, but this correlation was only observed when all the treatment were analysed together or when drought was simulated at heading.

The yield and water use properties of the wheat cultivars examined in the present work were investigated at various water supply levels at ambient carbon dioxide concentration by Varga et al. (2015). Both the present study and the earlier work showed that genotype and water withholding both had a substantial effect on the yield, and in some cultivars this was more pronounced in the case of elevated $\mathrm{CO}_{2}$ concentration, particularly when water supplies were limited. The direction in 
which higher $\mathrm{CO}_{2}$ concentration influenced the yield compared to that of the control plants depended basically on the phenophases in which the plants were exposed to the stress, as also reported by Mitchell et al. (1993). In the present work the yields tended to be lower than those described for the same cultivars in previous papers (Varga et al. 2013, Varga et al. 2015), and the quantity of water consumed during the vegetation period was also lower. The values of WUE were higher than those found for these cultivars in the previous work, while water withholding resulted in a smaller reduction in WUE, especially for the cultivars BKT and CAP. Although the present study demonstrated that a rise in the $\mathrm{CO}_{2}$ concentration improved the WUE values, there were differences between the cultivars as to whether the best WUE values were obtained at 700 or $1000 \mathrm{ppm}$. However, despite these differences in the absolute values, the differences between the cultivars remained the same, and in response to water withdrawal the direction and magnitude of the changes also agreed with those previously published.

\section{Acknowledgements}

The present study was co-funded by the TÁMOP 4.2.4.A/2-11-1-2012-0001 project and the TÉT_12_DE-1-2013-0012 project.

\section{References}

Aljazairi, S., Nogues, S., 2015: The effects of depleted, current and elevated $\mathrm{CO}_{2}$ in wheat are modulated by water availability. Environ. Exp. Bot. 112, 55-66.

Bencze, S., Veisz, O., Janda, T., Bedő, Z., 2000: Effects of elevated $\mathrm{CO}_{2}$ level and $\mathrm{N}$ and $\mathrm{P}$ supplies on two winter wheat varieties in early developmental stage. Cereal. Res. Commun. 28, 123-130.

Bender, J., Weigel, H.J., 2011: Changes in atmospheric chemistry and crop health: A review. Agron. Sustain. Dev. 31, 81-89. 
Blum, A., 2005: Drought resistance, water-use efficiency, and yield potential are they compatible, dissonant, or mutually exclusive? Aust. J. Agric. Res. 56, 1159-1168.

Dahal, K., Knowles, V.L., Plaxton, W.C., Hüner, N.P.A., 2014: Enhancement of photosynthetic performance, water use efficiency and grain yield during long-term growth under elevated $\mathrm{CO}_{2}$ in wheat and rye is growth temperature and cultivar dependent. Environ. Exp. Bot. 106, 207-220.

Doorenbos, J., Pruitt, W.O., 1977: Crop Water Requirements, Irrigation and Drainage Paper 24. Food and Agricultural Organisation of the United Nations, Rome, Italy.

Ehdaie, B., Layne, A., Waines, J., 2012: Root system plasticity to drought influences grain yield in bread wheat. Euphytica, 186, 219-232.

Evans, R.G., Sadler, E. J., 2008: Method and technologies to improve efficiency of water use. Water Resour. Res. 44, 1-15.

Ewert, F., Rodrigez, D., Jamieson, P., Semenov, M.A., Mitchell, R.A.C., Goudriaan, J., Porter, J.R., Kimball, B.A., Pinter, P.J., Manderscheid, R., Weigel, H.J., Fangmeier, A., Fereres, E., Villalobos, F., 2002: Effect of elevated $\mathrm{CO}_{2}$ and drought on wheat: testing crop simulation models for different experimental and climatic conditions. Agric. Ecosyst. Environ. 93, 249-266.

Ewert, F., Rounsevell, M.D.A., Reginster, I., Metzger, M.J., Leemans, R., 2005: Future scenarios of European agricultural land use I. Estimating changes in crop productivity. Agric. Ecosyst. Environ. 107, 101-116.

Fang, S., Cammarano, D., Zhou, G., Tan, G., Tan, K., Ren, S., 2015: Effects of increased day and night temperature with supplemental infrared heating on winter wheat growth in North China. Eur. J. Agron. 64, 67-77.

Francia, E., Tondelli, A., Rizza., B.F., Nicosia, O., Akat, T., 2011: Determinants of barley grain yield in a wide range of Mediterranean environments. Field Crops Res. 120, 169-178.

Guo, R., Lin, T., Mo, X., Yang, C., 2010: Responses of crop yield and water use efficiency to climate change in the North China Plain. Agric. Water Manage. 97, 1185-1194. 
Harnos, N., Bencze, S., Janda, T., Juhász, A., Veisz, O., 2002: Interaction between elevated $\mathrm{CO}_{2}$ and water stress in two winter wheat cultivars differing in drought resistance. Cereal. Res. Commun. 30, 359-366.

Hoffmann, B., 2008. Alteration of drought tolerance of winter wheat caused by translocation of rye chromosome segment 1RS. Cereal Res. Commun. 36, 269-278.

Hunsaker, D.J., Kimball, B.A., Pinter, P.J., LaMorte, R.L., Wall, G.W., 1996: Carbon dioxide enrichment and irrigation effects on wheat evapotranspiration and water use efficiency. Trans. ASAE. 39, 1345-1355.

Jabran, K., Ullah, E., Hussain, M., Farooq, M., Zaman, U., Yaseen, M., Chauhan, B.S. 2015: Mulching improves water productivity, yield and quality of fine rice under watersaving rice production systems. J. Agron. Crop Sci. 201, 389-400.

Kang, S., Zhang, L., Liang, Y., Hu, X., Cai, H., Gu, B., 2002: Effects of limited irrigation on yield and water use efficiency of winter wheat in the Loess Plateau of China. Agric. Water Manage. 55, 203-216.

Kimball, B.A., Kobayashi, K., Bindi, M., 2002: Responses of agricultural crops to free-air $\mathrm{CO}_{2}$ enrichment. Adv. Agron. 77, 293-368.

Li, D., Liu, H., Qiao, Y., Wang, Y., Cai, Z., Dong, B., Shi, C., Liu, Y., Li, X., Liu, M., 2013: Effects of elevated $\mathrm{CO}_{2}$ on growth, seed yield and water use efficiency of soybean (Glycine max (L.) Merr.) under drought stress. Agric. Water Manage. 129, 105-112.

Li, F.S., Kang, S.Z., Zhang, J., Cohen, S., 2003: Effects of atmospheric $\mathrm{CO}_{2}$ enrichment, water status and applied nitrogen on water- and nitrogen-use efficiencies of wheat. Plant Soil. 254, 279-289.

Lin, Y., Zeng, Z., Ren, C., Hu, Y., 2012: Water use efficiency and physiological responses of oat under alternate partial root-zone irrigation in the semiarid areas of northeast China. Procedia Engineering. 28, 33-42.

Liu, X., Shao, L., Sun, H., Chen, S., Zhang, X., 2013: Responses of yield and water use efficiency to irrigation amount decided by pan evaporation for winter wheat. Agric. Water Manage. 129, 173-180. 
Mitchell, J.H., Siamhan, D., Wamala, M.H., Risimeri, J.B., Chinyamakobvu, E., Henderson, S.A., Fukai, S., 1998: The use of seedling leaf death score for evaluation of drought resistance of rice. Field Crop. Res. 55, 129-139.

Mitchell, R.A.C., Mitchell, V.J., Driscoll, S.P., Franklin, J., Lawlor, D.W., 1993: Effects of increased $\mathrm{CO}_{2}$ concentration and temperature on growth and yield of winter wheat at two levels of nitrogen application. Plant Cell Environ. 16, 521-529.

Morell, F.J., Lampurlanés, J., Álvaro-Fuentes, J., Cantero-Martinez, C., 2011: Yield and water use efficiency of barley in a semiarid Mediterranean agroecosystem: Longterm effects of tillage and $\mathrm{N}$ fertilization. Soil Till. Res. 117, 76-84.

Ottman, M.J., Kimball, B.A., Pinter, P.J., Wall, G.W., Vanderlip, R.L., Leavitt, S.W., LaMorte, R.L., Matthia, A.D., Brooks, T.J., 2001: Elevated $\mathrm{CO}_{2}$ increases sorghum biomass under drought conditions. New Phytol. 150, 261-273.

Parry, M.L., Fischer, C., Livermore, M., Rosenzweig, C., Iglesias, A., 1999: Climate change and world food security: a new assessment. Glob Environ. Change. 9, 51-67.

Parry, M.L., Rosenzweig, C., Iglesias, A., Livermore, M., Fischer, G., 2004: Effects of climate change on global food production under SRES emissions and socioeconomic scenarios. Glob. Environ. Change, 14, 53-67.

Passioura, J.B., 2002: Environmental biology and crop improvement. Funct. Plant Biol. 29, $537-546$.

Passioura, J.B., 2012: Phenotyping for drought tolerance in grain crops: when is it useful to breeders? Funct. Plant Biol. 39, 851-859.

Pask, A.J.D., Reynolds, M.P., 2013: Breeding for yield potential has increased deep soil water extraction capacity in irrigated wheat. Crop Sci. 53, 2090-2104.

Qiu, G.Y., Wang, L., He, X., Zhang, X., Chen, S., Chen, J., Yang, Y., 2008: Water use efficiency and evapotranspiration of winter wheat and its response to irrigation regime in the North China Plain. Agric. For. Meteorol. 148, 1848-1859. 
Rizza, F., Ghashghaie, J., Meyer, S., Matteu, L., Mastrangelo, A.M., Badeck, F.W. 2012: Constitutive differences in water use efficiency between two durum wheat cultivars. Field Crops Res. 125, 49-60.

Robredo, A., Pérez-López, U., de la Maza, H.S., González-Moro, B., Lacuesta, M., MenaPetite, A., Muňos-Rueda, A., 2007: Elevated $\mathrm{CO}_{2}$ alleviates the impact of drought on barley improving water status by lowering stomatal conductance and delaying its effects on photosynthesis. Environ. Exp. Bot. 59, 252-263.

Rogers, H.H., Runion, G.B., Krupa, S.V., 1994: Plant responses to atmospheric $\mathrm{CO}_{2}$ enrichment with emphasis on roots and the rhizosphere. Environ. Pollut. 83, 155189.

Semenov, M.A., Stratonovitch, P., 2013: Designing high-yielding wheat ideotypes for a changing climate. Food Energy Secur. 3, 185-196.

Shahbaz, K., Munir, A.H., Mu, J.X., 2009: Water management and crop production for food security in China: a review. Agric. Water Manage. 96, 349-360.

Singh, R.V., Chauhan, S.P.S., 1991: Response of barley to the levels and sources of nitrogen with and without zinc in relation to yield and water use under dryland conditions. Bhartiya Krishi Anusandhan Patrika 6, 43-48.

Tausz-Posch, S., Dempsey, R.W., Seneweera, S., Norton, R.M., Fitzgerald, G., Tausz, M., 2015: Does a freely tillering wheat cultivar benefit more from elevated $\mathrm{CO}_{2}$ than a restricted tillering cultivar in water-limited environment? Eur. J. Agron. 64, 21-28.

Tischner, T., Köszegi, B., Veisz, O., 1997: Climatic programmes used in the Martonvásár phytotron most frequently in recent years. Acta Agron. Hung. 45, 85-104.

Tuba, Z., Lichtenthaler, H.K., 2007: Long-term acclimation of plants to elevated $\mathrm{CO}_{2}$ and its interaction with stresses. Ann. Ny. Acad. Sci. 1113, 135-146.

Tuberosa, R., 2012: Phenotyping for drought tolerance of crops in the genomics era. Front. Plant Physiol, 347, 1-25. 
Varga, B., Varga-László, E., Bencze, S., Balla, K., Veisz, O., 2013: Water use of winter cereals under well watered and drought stressed conditions. Plant Soil Environ. 59, $150-155$.

Varga, B., Vida, G., Varga-Laszlo, E., Bencze, S., Veisz, O., 2015: Effect of simulating drought in various phenophases on the water use efficiency of winter wheat. J. Agron. Crop Sci. 201, 1-9.

Wall, G.W., 2001: Elevated atmospheric $\mathrm{CO}_{2}$ alleviates drought stress in wheat. Agric. Ecosyst. Environ. 87, 261-271.

Zadoks, J.C., Chang, T.T., Konzak, C.F., 1974: A decimal code for the growth stage of cereals. Euphytica Bull. 7, 42-52.

Zhang, X., Wang, Y., Sun, H., Chen, S., Shao, L., 2013: Optimizing the yield of winter wheat by regulating water consumption during vegetative and reproductive stages under limited water supply. Irrig. Sci. 31, 1103-1112.

Zhang, H., Wang, X., You, M., Liu, C., 1999: Water yield relations and water-use efficiency of winter wheat in the North-China Plain. Irrig. Sci. 19, 37-45.

Zhang, X., Chen, S., Sun, H., Pei, D., Wang, Y., 2008: Dry matter, harvest index, grain yield and water use efficiency as affected by water supply in winter wheat. Irrig. Sci. 27, $1-10$ 